\title{
Government Consumption and Private Consumption Correlations
}

\author{
Jane Marrinan * \\ Department of Economics, Universitat Pompeu Fabra \\ Ramon Trias Fargas, 25-27, 08005 Barcelona, Spain
}

This revision: October 24, 1996

\begin{abstract}
This paper examines whether the introduction of government consumption expenditure in a standard one good model of the international real business cycle is sufficient to reconcile the theory with the existing pattern of international consumption and output correlations. I calibrate the model to two different pairs of countries and generate the simulated distribution of consumption and output correlations implied by several specifications of the model. It is shown that the model can account for existing international consumption correlations only under very specific assumptions about the size of effect of government expenditure on agents' utility or the variability of government expenditure shocks. Crucial parameters are identified and the sensitivity of the results discussed.
\end{abstract}

Journal of Economic Literature Classification Nos.: E32, F41

Key Words: Government Expenditure, Risk Sharing, Consumption Correlations, International Real Business Cycles.

*I would like to thank two anonymous referees for comments and suggestions. 


\section{Introduction}

In a recent paper Deveraux, Gregory and Smith (DGS) (1992) have argued that existing cross country consumption correlations are at odds with the properties of a one good, stationary, ArrowDebreu model. In that economy when agents have identical and homothetic preferences, cross country private consumption correlations are perfect in the face of idiosyncratic output fluctuations. This is because with markets for all dates and all states of the world agents of each country can perfectly insure themselves by writing contingent claims so as to eliminate individual idiosyncratic risk and bear only aggregate (nondiversifiable) risk. DGS report consumption correlations across a number of countries using different detrending transformations designed to extract the cyclical component of private consumption. They find that correlations are significantly different from one, in some cases quite low and for all countries considerably lower than output correlations. Backus, Kehoe and Kydland (BKK) (1992), Baxter and Crucini (1993) and Canova and Ravn (1996), among others, have documented a similar pattern using different data sets, different time periods and different estimation techniques.

The large discrepancy of the theory from the data has prompted Backus, Kehoe and Kydland (1995) to term the magnitude of cross country consumption correlations relative to output correlations as one of the major unexplained puzzles of the international business cycle literature. The relatively low value of the consumption correlation has also generated substantial discussion in policy circles where it has been suggested that there is a need for international government institutions providing additional risk sharing arrangements for agents of different countries (see e.g. Persson and Tabellini (1996)). To reduce the discrepancy between theory and data and better understand why actual economies deviate from the simple Arrow-Debreu paradigm, the standard one good model has been extended in several dimensions. For example, Stockman and Dellas (1989), Tesar (1993) and Van Wincoop (1993) have introduced non-traded goods; DGS (1992) have modified the preference specification commonly used in the literature; Kollman (1995) and Baxter and Crucini (1995) have introduced capital controls or incomplete markets. While the first two modifications have been partially successful, limiting trade in financial assets has failed to produce the rela- 
tive ordering of international consumption and output correlations and the absolute magnitude of cross country consumption correlations we observe in the data unless the discount factor of the representative agent is also endogenized.

In this paper I examine whether one alternative modification of the basic model is more successful in quantitatively reproducing the behavior of actual data. I introduce a government sector in the economy and examine the effects of government expenditure shocks on international consumption and output correlations. Several studies, including Aiyagari, Christiano, Eichenbaum (1992), Christiano and Eichenbaum (1992) and Baxter and King (1993), have examined the effects of government consumption expenditure in closed economies. Van Wincoop and Marrinan (1996) extended the analysis to open economies by studying the implications of government spending and taxation for private and public cross country savings and investment decisions. Baxter (1993) has studied how government expenditure disturbances are transmitted across countries. It is therefore worthwhile to examine whether the presence of government consumption expenditure in the model is an important element to understand the pattern of international private consumption correlations. If this modification is proved successful in quantitatively reproducing the features of actual data we are interested in, it may also provide rationale for models of international risk sharing where a countercyclical government expenditure helps to insure, directly or indirectly, domestic consumers from imported shocks.

The model features a single good, which is produced in both countries, and a government sector which consumes a fraction of the goods produced in its own country. Government expenditure provides utility to domestic agents in the form of a flow of services from the goods which are consumed. Government expenditure shocks therefore have two types of effects: a "wealth" effect through the budget constraint and a "substitution" effect through the utility function of the representative agent. Although these two effects produce different dynamics for investment, labor supplies and outputs, they both go in the direction of generating negative correlations between changes in government consumption and changes in private consumption. Because government consumption expenditure and private consumption are imperfect substitutes in utility and because the flow of services government expenditure generates cannot be relocated internationally, it es- 
sentially plays the role of a non-traded consumption good. Therefore, disturbances to government expenditure drive a wedge between the time profile of domestic and foreign consumptions. This reduces international private consumption correlations even when international financial markets are complete since risk sharing pertains to full consumption (private plus government consumption), and may in principle help to account for the low international consumption correlations we observe in actual data. Note that the specification used here differs from Stockman and Tesar (1995) who use private taste shocks to produce the substitution type of effects discussed above and from BBK (1993) who consider only the wealth effect of government shocks via the budget constraint.

Although the mechanism just described is appealing, the crucial question I address in this paper is whether realistic government expenditure processes are quantitatively able to bring simulated private international consumption correlations in the range of what we observe in the data and replicate the relative magnitude of international consumption and output correlations. To answer this question I calibrate the model to two different pairs of countries (US vs. Canada and US vs. Europe) and, as in DGS (1992), I generate the simulated distribution of cross country consumption and output correlations implied by different specifications of the model. In order to compute meaningful cross country correlations, it is necessary to render the series stationary. Because existing evidence and available econometric technology do not allow us to confidently choose one procedure over another (on this point, see Canova (1993)), I study the implications of the model for international consumption correlations using three alternative detrending procedures, each of which is applied both to actual and simulated data.

I show that when government consumption provides utility enhancing services for domestic agents, a model where government shocks are the only disturbances in the economy has some potential to reproduce the cross sectional range of international consumption and output correlations we observe in the data, regardless of the detrending method employed. To do so, however, we need a sufficiently high level of substitutability between private consumption and government consumption, above the value estimated by Kormendi (1983) or Ashauer (1985). However, when government consumption expenditure does not affect utility of domestic agents, there is no specification of the model that can reproduce the pattern of international consumption and output correlations we see 
in the data (consistent with the results of BBK (1995)). These results are not too sensitive to the size of the countries or to alternative settings of some unmeasured parameters within a reasonable range. There are however two crucial parameters (the risk aversion parameter and the parameter of the adjustment cost function) which determine both the shape and the location of the simulated distribution of consumption and output correlations. By pinning down these parameters with more precision we may therefore improve our understanding of the properties of these models for the question of interest. Finally, I demonstrate that when both government and productivity disturbances are present, the variability of government expenditure disturbances must be about 100 times larger than what we see in the data and about 25 times larger than the variability of productivity disturbances for the model to come close to reproduce existing cross country correlations for each pair of countries we consider.

The paper is organized as follows. The next section presents empirical evidence concerning the size of international consumption and output correlations and discusses some issues connected with measurement errors in consumption. Section 3 presents the model and section 4 discusses its calibration. Section 5 presents the results and section 6 concludes.

\section{Some Empirical Evidence}

The characteristics of international consumption and output correlations are, by now, well documented and understood (see e.g. BKK (1992), DGS (1992) or Canova and Ravn (1996)). In this section I therefore only briefly outline the general features of the phenomenon and discuss some issues connected with the presence of measurement error in consumption data.

Since both consumption and output data appear to be nonstationary and not cointegrated, a meaningful bilateral cross country correlation analysis can be computed only after trends are removed from the series. The existing literature has proposed several ways to decompose a series into trend and cycle, all of which are reasonable given existing time series technology and the available data samples. Canova (1993) emphasizes that different detrending methods induce substantially different moments for the cyclical component of the data. In particular, he shows that both the absolute and relative magnitude of variabilities, the size of the correlations with GNP and the size 
and the pattern of impulse responses are all sensitive to the choice of trend removal procedure. To examine whether the quantitative ability of the model to replicate the data depends on the procedure used to remove the trend, I examine three detrending approaches: the first removes a linear trend (LT filter), the second a stochastic but smooth trend (Hodrick and Prescott (HP) filter with $\lambda=1600$ ) and the third a stochastic unit root trend (first order differencing (FOD) filter). As noted in Canova and Ravn (1996), each of these methods leaves cycles of different average duration in the data: LT filtering leaves cycles of average duration of about 8-10 years in the data, HP filtering cycles of average duration of about 4-6 years and FOD filtering cycles of average duration of about 2-3 years. Therefore, by comparing the results across detrending methods, we not only perform a basic sensitivity analysis needed because the properties of the trend are unknown, but also study the strength of the cross country association of consumptions and outputs for cycles of different duration.

Table 1 reports pairwise consumption correlations for 9 OECD countries. Panel A contains the results for LT filtered data, Panel B for HP filtered data and Panel C for FOD filtered data. In each panel, the standard deviations of the correlations are in parenthesis. Table 2 reports the same information for pairwise output correlations. The data and their sources are described in detail in the appendix.

Table 1 shows several interesting regularities. First, the size of the cross country consumption correlation does change with the detrending method: it is higher when the cyclical component contains cycles of longer average duration (median value 0.393 and maximum 0.826 ) and almost zero when cycles of only 2-3 years are considered (median value 0.154 and maximum 0.531 ). To formally confirm this impression I test whether consumption correlations are similar across detrending methods. For this purpose I use a distance test of the form $J=\left[\operatorname{corr}(i, j)^{q}-\operatorname{corr}(i, j)^{p}\right]\left(\operatorname{var}\left(\operatorname{corr}(i, j)^{q}\right)+\right.$ $\operatorname{var}\left(\operatorname{corr}(i, j)^{p}\right)^{-1}\left[\operatorname{corr}(i, j)^{q}-\operatorname{corr}(i, j)^{p}\right]$ where $\operatorname{corr}(i, j)^{p}$ and $\operatorname{corr}(i, j)^{q}$ is the consumption correlation between country $i$ and $j$ using detrending method $p, q=H P, L T, F O D$. Under the null of equality, $J$ is distributed as a $\chi^{2}(1)$. Not surprisingly, the test rejects the null hypothesis in all cases. Second, within each panel, the magnitude of cross-country consumption correlations for all pairs of countries is comparable even though the correlation among pairs of European countries 
appears to be larger than the correlation among the other countries of the panel. Finally, for all detrending methods, consumption correlations are significantly different from one at standard significance levels.

The fact that international consumption correlations are significantly different from one is not per-se to be taken as a rejection of the complete market Arrow-Debreu assumption. If factors other than consumption of tradables affect utility (e.g. home production or leisure), theoretical consumption correlations will be different from one as explained in Canova and Ravn (1996). The puzzle concerns the size of consumption correlations relative to output correlations. Comparing tables 1 and 2 we see that consumption correlations are always lower than output correlations when the HP filter is used to detrend the data (median values 0.282 and 0.412 respectively). However, with the other two filters, there are many cases where consumption and output correlations are similar in magnitude (and statistically not significantly different) and in some cases consumption correlations even exceed output correlations (in particular, with LT method). This suggests that the relative magnitude of cross country consumption and output correlations changes across frequencies: on average consumption correlations are larger than output correlations for cycles of 8-10 years, they are smaller for cycles of 4-6 years and approximately of the same magnitude for cycles of 2-3 years.

Although the basic features of the consumption correlations presented appear to be robust within each panel, one should be very careful in viewing them as established empirical regularities which should be rationalized by a model. First, the only consumption data which is consistently available across countries on a quarterly basis measures total (durables and non-durables) consumption expenditure by domestic residents. As will become clear in the next section, the consumption we measure in the model has no durability aspects so the matching of the model to the data is imperfect. One way out of this impasse is to include durable consumption goods in the model, as e.g. in Dunn and Singleton (1986). Because the level of complication introduced by this additional feature is substantial, I do not follow this approach. One simple alternative is to verify that the proportion of durables to nondurables in consumption is stable over time and that the variability of the two components is not too different. If this is the case, the correlation properties of total 
consumption will not be very different from those of nondurables and services. For those countries for which disaggregated consumption data exist (US, UK, Japan, France) I do find that the proportion of durables in total consumption expenditure is increasing, but not substantially. However, the variability of the two components differs, with durables being more cyclical than nondurables and services. This may therefore induce an upward bias in the estimates we report in panels $\mathrm{A}$ and B of table 1. Nevertheless, the order of magnitude of the difference is not so large as to cause great concern. For example, the correlation between US and UK consumption of nondurables is at most $10 \%$ different from the correlation of total consumption, regardless of the detrending method ${ }^{1}$.

\section{The Model}

The model we employ to account for the existing pattern of consumption and output correlations is the same as in Baxter and Crucini (1993). It is a two-country model with a single consumption good. Each country is populated by a large number of identical agents and labor is assumed to be immobile across countries. Preferences of the representative agent of country $h=1,2$ are given by:

$$
U \equiv E_{0} \sum_{t=0}^{\infty} \frac{\beta^{t}}{1-\sigma}\left[c_{h t}^{* \theta} l_{h t}^{(1-\theta)}\right]^{1-\sigma}
$$

where

$$
c_{h t}^{*}=c_{h t}+z_{h t}
$$

where $c_{h t}$ is private consumption of the single composite good by the representative agent of country $h$ and $z_{h t}=\mu_{g} g_{h t}$ where $g_{h t}$ measures real government consumption in country $h$ and $\mu_{g}$ is a constant

\footnotetext{
${ }^{1} \mathrm{~A}$ second and more important problem concerns the measurement of consumption. It is well known that consumption data sampled at fine intervals contains a substantial amount of measurement error which is correlated over time. This measurement error may blur the true features of cross country consumption correlations. In addition, as noted by Wilcox (1992), measurement error may be a more severe problem than previously noted because quarterly consumption data are interpolated by statistical agencies using consumption measurements obtained every five years and monthly sales data. Apart from the statistical distortions which may be introduced because of this interpolation (e.g. consumption may be excessively smooth), it may well be that different countries use different interpolating algorithms and that the actual measurement of consumption is undertaken at different points in time. This last possibility is particularly problematic since the true features of actual consumption correlations may be completely distorted when series with different base years are interpolated and compared. Because no information is available on this issue, I undertake no adjustment. However, it should be clear that the presence of measurement errors in consumption both within and across countries constitutes a serious problem when it comes to verifying the empirical validity of a theoretical model, especially when the frequency of available data does not correspond to the frequency of agents' decisions.
} 
parameter determining the substitutability (or the complementarity) between private and public expenditure (as in Ashauer (1985)).

There are many ways in which government activity may affect private decisions. Ashauer (1989), Barro and Sala-i-Martin (1990) and Baxter and King (1993) have considered how the provision of infrastructures and other expenditures in public capital formation affect the productivity of private factors and private output. Here I follow another strand of literature, initially considered by Barro (1981) and further examined by Ashauer (1985), Barro (1989) and others: government expenditure on goods and services is not productive but yields direct utility for the agents of their own country via a linear technology which transforms government consumption into consumption goods for private use. When $\mu_{g}=0$ government $h$ consumption does not affect utility, while when $0<\mu_{g} \leq 1$, government and private domestic consumption are substitutes and when $\mu_{g}<0$ they are complements. Also, when $\mu_{g}<1$, it is costly for society to have the government "produce" goods for private consumption.

Intuitively, one can think of $g_{h t}$ as military expenditure, as in Baxter and King (1993), as federal civilian spending (e.g. educational subsidies), as in Graham (1993) or both. Whichever interpretation one takes, I make the strong but convenient assumption that government consumption expenditure on different categories of goods has the same effect on the marginal utility of consumption. In other words, if $g_{h t}$ includes both military expenditure and educational subsidies, $\mu_{g}$ is the same for both types of expenditures (see Kormendi (1983) for some empirical evidence concerning the size of $\mu_{g}$ across types of government expenditures). The goods are produced with a Cobb-Douglas technology:

$$
Y_{h t}=A_{h t}\left(K_{h t}^{\alpha}\right)\left(X_{h t} N_{h t}\right)^{1-\alpha} \quad h=1,2
$$

where $X_{h t}=\gamma X_{h t-1} \forall h$ with $\gamma \geq 1 . X_{h t}$ represents labor-augmenting Harrod-neutral technological progress with deterministic growth rate equal to $\gamma$. Production requires domestic labor and capital inputs and is subject to a technological disturbance $A_{h t}$ whose properties will be described later on. 
Capital goods are accumulated according to:

$$
K_{h t+1}=\left(1-\delta_{h}\right) K_{h t}+\psi\left(I_{h t} / K_{h t}\right) K_{h t} \quad h=1,2
$$

where $\psi\left(\frac{I_{h t}}{K_{h t}}\right)>0$ is concave and represents the cost of installing new capital or moving new capital from the location where it is produced to the other country. These transaction costs help to avoid unrealistically large cross border capital movements in response to technological disturbances. The formulation for the adjustment cost function is similar to Baxter and Crucini (1993) and is chosen because it retains simplicity, while linking transaction costs to Tobin's $Q \cdot \frac{1}{\psi^{\prime}}$ is in fact Tobin's $Q$, i.e. the price of existing capital in one location relative to the price of new capital.

Leisure choices are constrained by:

$$
0 \leq l_{h t}+N_{h t} \leq 1 \quad \forall h
$$

where the total endowment of time in each country is normalized to 1.

Governments finance their consumption purchases by taxing national outputs with a distorting tax and then transferring what remains back to domestic residents. It is assumed that government expenditure is stochastic, while tax rates are parametrically given. Although there are models (see e.g. Braun and McGrattan (1993) or van Wincoop and Marrinan (1996)) where tax rates are stochastic, here I adopt a parametric representation in order to isolate the contribution of government expenditure disturbances to the solution of the international consumption correlation puzzle. Further, I assume that the government budget constraint is balanced on a period by period basis. Because the economy is Ricardian, the addition of one period government bonds to the financing possibilities of the governments will not change equilibrium allocations. The government budget constraint is given by:

$$
g_{h t}=T R_{h t}+\tau_{h} Y_{h t} \quad \forall h
$$

where $\tau_{h}$ are tax rates and $T R_{h}$ are lump sum transfers in country $h$.

The economy wide resource constraint is given by:

$$
\pi\left(Y_{1 t}-g_{1 t}-c_{1 t}-k_{1 t+1}\right)+(1-\pi)\left(Y_{2 t}-g_{2 t}-c_{2 t}-k_{2 t+1}\right) \geq-\pi\left(1-\delta_{1}\right) k_{1 t}-(1-\pi)\left(1-\delta_{2}\right) k_{2 t}
$$


where we have implicitly accounted for the fact that new investment is costly and where $\pi$ is the share of agents living in country 1 . The world economy is subject to a $4 \times 1$ vector of shocks $w_{t}=\left[A_{h t}, g_{h t}\right]$ where $w_{t}$ is a homoskedastic process with conditional mean $E_{t}\left(w_{t}\right)=\rho w_{t-1}$ and variance $\Omega$.

There is some empirical evidence (Costello (1993)) that productivity disturbances have small but important cross country lagged effects which are asymmetric and that they are somewhat contemporaneously correlated. There is also some evidence that productivity disturbances and government expenditure shocks may be negatively correlated within countries (see Finn (1991) or Christiano and Eichenbaum (1992)). To account for these effects I let the $\rho$ and $\Omega$ matrices have a general structure and perform simulations for various restricted specifications.

Finally, as in BKK (1992) and Baxter and Crucini (1993), I assume complete financial markets and free mobility of financial capital across countries. While this assumption may appear unrealistic, it provides a useful benchmark to evaluate the model in the ideal situation where frictions, in the form of transaction costs, appear only in the goods market (for an alternative setup see Baxter and Crucini (1995) or Kollman (1995)).

To find a solution to the model I first detrend those variables which drift over time by taking ratios of the original variables with respect to the labor augmenting technological progress, e.g. $y_{h t}=\frac{Y_{h t}}{X_{h t}}$, etc. Second, since there are distortionary taxes in the model, the competitive equilibrium is not Pareto optimal and the competitive solution differs from the social planner's solution. To solve for the competitive equilibrium I therefore solve the problem faced by a pseudo social planner, modifying the optimality conditions to take care of the distortions. The weights in the social planner problem are free parameters. For countries which are otherwise identical, they will be chosen to be proportional to the initial population size of each country. The modified optimality conditions are then approximated with a log-linear expansion around the steady state as in King, Plosser and Rebelo (1988). Time series for aggregate consumption and output in each country are computed analytically from the approximate optimality conditions and international correlations are computed by passing simulated time series through the same three detrending methods we have used on the actual data. 


\section{Calibration and Some Discussion}

To facilitate the comparison with the existing literature, the model is calibrated to two situations, one where the two countries have the same stochastic driving processes as the US and Canada (as in DGS (1992)) and one where they replicate the stochastic processes of the US and Europe (as in BKK (1992)). These two situations represent two very diverse environments since the US has a share of world output which is ten times as large as Canada (42.8\% vs $4.1 \%)$ while it has about the same share of world output as the EEC ( $42.8 \%$ vs $37.1 \%$ ). Note also that the deep parameters of the model calibrated to the long run averages of the data in the three economies are very similar (see e.g. DGS (1992), BBK (1992), Mendoza (1991), Cardia (1991) or Canova and Marrinan (1996)). This helps to justify the abstraction of taking the countries in the artificial economy to be identical in terms of preferences and technologies while allowing for some heterogeneity in the specifications of their exogenous driving forces.

Many of the parameters used in the two situations, which we present in table 3 , are very similar to those employed in the above studies and do not require much discussion: $\gamma_{x}$, the labour augmenting technological progress is set to 1.004, the steady state level of hours $\bar{N}$ to 0.2 , the steady state share of government expenditure in output $s_{g}$ to 0.2 , the tax rate $\tau$ to 0.3 , the share of labor in the production function $(1-\alpha)$ to 0.58 for the US-Canada pair and to 0.60 for the US-Europe pair. Finally, the steady state real interest rate $R$ is set to $6.5 \%$ per year. Those parameters for which no previous measurement is available are fixed a-priori. These parameters are: $\xi$, the elasticity of the investment-capital ratio to Tobin's $Q$, which is set to -0.075 , the steady state value of Tobin's

Q, set equal to 1.0, both of which are the values employed by Baxter and Crucini (1993), and the depreciation of capital, set equal to 0.025 per quarter. Finally, following tradition in the empirical real business cycle literature, the risk aversion parameter, $\sigma$, is set equal to 2 .

Kormendi (1983), Ashauer (1985) and Barro (1989) have estimated $\mu_{g}$ from various data sets obtaining values in the range $[0.23,0.45]$ depending on the specification of the model, the sample period and the categories of goods included in $g_{h t}$. Recently Graham (1993) has found a much larger range of values with an average estimate close to zero and some situations where $\mu_{g}$ is estimated 
to be negative. Because of this large variety of estimates, I decided to report the results obtained in five subcases, indexed by the value of $\mu_{g}\left(\mu_{g}=0,0.2,0.5,0.8\right.$ and 1.0$)$, and examine whether the exact choice of $\mu_{g}$ makes a difference.

The initial set of simulations are performed for a situation where countries differ only in their size, in which case $\rho$ and $\Omega$ are symmetric. The parameters for the process for technology disturbances are from BKK and DGS. The parameters for government disturbances are from my own estimates. At a second stage I also allow some asymmetries in the exogenous processes across countries.

As emphasized in Gregory and Smith (1991), Canova (1994) and others, to take the conclusions of calibration exercises seriously one must provide some analysis of the sensitivity of the results to variations of the parameters in a neighborhood of the calibrated values. This is because conclusions drawn from this type of exercise often neglect the fact that a calibrator has available only estimates of the parameters of interest (and in some cases not even that) and that parameter uncertainty and selection biases may be important in determining the quality of the results. For this reason, I undertake an informal sensitivity analysis on the outcomes of the model by replicating the basic set of experiments for values of the parameters within a reasonable range. Here, I will present sensitivity results when I vary some of the private sector parameters which are fixed a-priori $(\xi, \sigma)$, and some of the parameters of the AR representation of the disturbances and their covariance matrix.

In describing the outcomes of the experiments I adopt the same probabilistic approach of DGS and present the approximate $90 \%$ confidence interval (constructed from the 5th to the 95th percentile) of the empirical density functions of simulated cross country consumption correlations and output correlations. This range provides a measure of the spread of the simulated distributions which can be compared with a normal confidence range constructed from the entries of tables 1 and 2. To measure how far the model is from the data I also report a p-value which, for each model specification, represents the probability of finding a cross country correlation which is less than or equal to the corresponding sample cross country correlation. This p-value is the proportion of replications for which the simulated cross country correlation is less than the historical value. 
In other words, if $\bar{x}$ is the pairwise correlation of interest, I report $P[-\infty<x \leq \bar{x}]=\int_{-\infty}^{\bar{x}} p(x) d x$ where $p(x)$ is the empirical distribution of the simulated cross country correlations. In this way the sample cross country correlation is treated as a critical value in examining the validity of the theory. Values close to zero or one indicate that $\bar{x}$ is in one of the tails of the simulated distribution, in which case the model performs poorly in reproducing international correlations, while values close to 0.5 indicate that $\bar{x}$ is close to the median of the simulated distribution. In this latter case, the model does a good job in reproducing the data. Finally, values in the range $[0.05,0.95]$ indicate that the model is not significantly at odds with the data. To calculate this p-value, I generate 1000 samples of 170 observations, and use the actual values of consumption and output correlations between US and Canada and US and Europe (as reported by BBK (1992)) as critical values. Because the initial conditions for the capital stock are set arbitrarily, the initial 50 observations for each replication are discarded to eliminate initial condition problems.

\section{The Results}

The results of the basic experiments are presented in table 4. I consider three benchmark cases where the stochastic processes for the two countries are symmetric: one where only technology shocks are present, one where only government expenditure shocks are present and one where both types of disturbances are present. The right panel reports results for the case of two equally sized countries $(\pi=0.50)$, as would be the case approximately for the US and Europe, while the left panel reports results for the case of one country which is about ten times as large as the other $(\pi=0.90)$, as would be the case approximately, for US and Canada.

Several features of the table deserve comment. First, the results are only slightly sensitive to the size of the two countries and to the exact data generating process for the exogenous variables of the model. The range of consumption correlations is slightly higher when $\pi=0.9$ and when the driving processes are calibrated to match the properties of technology and of government expenditure disturbances in the US and Canada but differences are minor. This result may seem a little surprising in light of those obtained by Head (1992) or Baxter and Crucini (1993), where it is argued that when a country accounts for a large portion of world output it is less able to smooth 
its consumption profile by borrowing abroad because of its impact on world outputs and interest rates. However, it should be stressed that they consider only idiosyncratic shocks which are specific to the large country, while here we are considering disturbances to both countries which match the stochastic processes of the two types of disturbances we see in the data so results are not directly comparable.

Second, a model driven only by technology shocks generates (i) almost perfect international consumption correlations regardless of the size of the country and the autocorrelation properties of technology disturbances and (ii) a distribution of output correlations with a median value between 0.1 and 0.4 depending on the detrending method. Both are clearly at odds with the data. A model driven only by government expenditure shocks, on the other hand, has some potential to generate (i) the type of consumption correlations we observe in the data and (ii) the relative ranking of cross country consumption and output correlations. In particular, when $\mu_{g}$ is between 0.5 and 1.0 , the $90 \%$ confidence range for cross country consumption correlations generated by the model covers the cross-country range of observed international consumption correlations, regardless of the method employed to detrend the data. Moreover, cross country consumption correlations are, on average, smaller than output correlations for HP detrended data and as big as output correlations with LT and FOD detrended data.

Third, as $\mu_{g}$ increases, the importance of government expenditure shocks on private consumption correlations increases. To understand why this is the case it is useful to note that when the income effect on leisure is positive, government expenditure shocks have two effects on private agents' decisions. First, as government expenditure increases given investment, agents experience an income reduction (wealth effect) which induces them to work harder. This increases hours, output and makes private consumption fall. Second, increases in government expenditure induce direct changes on investment which, in turn, produce an indirect effect on hours, output and consumption. The sign of the direct effect on investments depends on whether changes in government expenditure are permanent or transitory. If the changes are permanent, steady state labor supply is shifted, investment increases and in the new steady state the capital/labor ratio is constant. If changes are transitory, investment decreases so that the composite change in hours and output is 
smaller relative to the change that occurs when shocks are permanent. In both cases domestic consumption drops and, because of risk sharing, foreign private consumption will decrease as well. Finally, the effect on foreign output depends on whether investment increases or decreases.

These are the dynamics following a government expenditure disturbance when government expenditure does not enter the utility function of agents. However, when $\mu_{g} \neq 0$ an increase in government expenditure increases private agents' utility. This increase has two consequences. First, because the wealth effect is smaller, changes in government consumption have a smaller effect on labor supply. Therefore, the lagged dynamics of the model are hampered. Second, because the reduction in private consumption is compensated for by the increase in government consumption, and because agents are indifferent between private and public consumption, private consumption decreases more relative to the case when $\mu_{g}=0$. This second effect is not shared across countries because, from the point of view of the domestic agent, marginal utility is unchanged. This implies that international private consumption correlations decrease while the correlation between $c_{1 t}^{*}$ and $c_{2 t}^{*}$ stays constant. For values of $\mu_{g}$ lower than 1 , the combined result of these two contrasting effects depends on the persistence and the variability of government expenditure shocks and on the spillover effects of the two shocks across countries. As $\mu_{g}$ approaches 1, government expenditure shocks do not induce lagged dynamics in the system, as their effect on labor supply and investment fades, and they perfectly crowd out private consumption.

This interesting feature of the model, which is present when government consumption shocks drive the economy, disappears when we allow for both government and technology disturbances to be present. With a realistic parameterization the generated consumption correlations are very similar to the ones generated by a model where only technology shocks are present in the economy. This does not come as a surprise since technology shocks are four times as volatile as government expenditure shocks and they clearly constitute the dominant source of fluctuations in the simulations.

Finally, the ability of the model to reproduce the data is not very sensitive to the detrending method employed. Hence, the differences we noted in table 1 are due to the fact that different detrending methods extract cycles of different duration from the data. When the data generated 
by the model is passed through the same filters used to detrend actual data, similar qualitative differences emerge.

To summarize, this first set of simulation results indicates that when only government consumption shocks drive the economy and $\mu_{g}$ is at some intermediate value between 0.5 and 1.0 , the model generates private consumption correlations which are within the range of international private consumption correlations found in the data and the ranking between cross country consumption and output correlations correctly reproduces the ranking we find in the real world. With the adopted parameterization, government consumption expenditure plays the role of a nontraded good which is nonseparable with private consumption in the utility of agents and can therefore drive a wedge between the time profile of private consumptions across countries. However, when only technology shocks drive the economy or when both government expenditure and technology shocks drive the economy, the model grossly fails to reproduce the data.

\subsection{A Sensitivity Analysis}

For sensitivity analysis I have examined how the distribution of simulated international consumption and output correlations changes when I vary some of the parameters which were either fixed apriori or measured with substantial error. I report only a subset of the simulations performed with the most interesting cases summarized in tables 5.1-5.4. The tables report the effects of increasing the adjustment cost parameter from $\xi=-0.075$ to $\xi=-0.01$, of increasing the risk aversion parameter $\gamma$ from 2.0 to 10.0 , of reducing the persistence and of increasing the variability of government expenditure disturbances, and of allowing the parameters of the exogenous processes to be country specific.

A comparison of tables 4 and 5.1 indicates that the results obtained are somewhat sensitive to the choice of the adjustment cost parameter. Increasing the value of the adjustment cost parameter has the effect of decreasing somewhat international consumption and output correlations regardless of the size of the country and, to a large extent, the source of disturbances. This should not come as a surprise since the higher are the costs of installing or moving capital, the lower is the incentive to smooth consumption via international trade in investment goods. In practice, by increasing this 
parameter to very high values we can generate arbitrarily low consumption and output correlations. However, because the value of -0.075 is such that the volatility of simulated investment relative to simulated output is approximately the same as the volatility of actual investment relative to actual output, it is clear that the range of "realistic" values of $\xi$ is relatively small.

Increasing the risk aversion parameter to a value similar to what is needed to solve the equity premium puzzle (see Mehra and Prescott (1985)) also has the effect of changing both the location and the spread of the simulated cross country consumption and output correlations, regardless of the detrending method employed. The direction of the changes, however, depends on the size of the countries: for $\pi=0.5$ the $90 \%$ range is smaller and the median is larger, for $\pi=0.9$ the opposite is true. Intuitively, these results occur because when risk aversion is higher, the intertemporal substitution of leisure, which is the engine generating most of the dynamics of the model when government expenditure shocks drive the economy, is lower. Hence, for a given value of $\mu_{g}$ and of the variability of the shocks, the crowding out effect of government disturbances is stronger the larger is the difference in the sizes of the two countries and the magnitude of simulated international consumption and output correlations is reduced.

The literature discussing the effects of government expenditure shocks in general equilibrium models had put substantial emphasis on the differential effects of transitory vs. persistent disturbances (see e.g. Barro (1981)). Recent work by Aiyagari, Christiano and Eichenbaum (1992) and Baxter and King (1993) suggests that there are not major qualitative differences between these two different types of government shocks and instead concentrates on the quantitative differences produced by different persistence parameters. Because these analyses were concerned with closed economy frameworks, we believe it is interesting to examine whether permanent and transitory government disturbances produce qualitatively different results for the questions of interest in this paper. Consistent with their conclusions, table 5.3 indicates that reducing the persistence of government disturbances does not change the qualitative features of our results. In particular, it is still the case that for $\mu_{g}$ around 0.8 and when only government disturbances exist, the model reproduces the data pretty well. However, when both disturbances are present, the importance of government disturbances for the magnitude of international consumption correlations fades. But, consistent 
with intuition, the more transitory government expenditure disturbances are, the more frequently a wedge between the time profile of domestic and foreign private consumption is generated, and, as a consequence, the lower are international private consumption correlations, given the size of the two countries, the adjustment cost parameter and the relative magnitude of the variances of the two types of disturbances. Note also that, as expected, cross country output correlations are smaller when $\rho_{g}$ decreases from 0.95 to 0.2 .

Next, I ask what is the variability of government expenditure disturbances that is needed in a model where both government expenditure and technology shocks are present to generate crosscountry consumption correlations which replicate the available evidence. I find, consistent with Ravn (1993), that only if the variability of government expenditure disturbances were 100 times larger than the one estimated from the data, would the model be able to replicate the quantitative features of international consumption correlations. To put the result in another way, to match actual consumption correlations and the relative ranking of international consumption and output correlations with a model where both government and technology shocks are present, we need a variability of government spending around $6 \%$ of its mean share, a value which is not observed in any industrialized country. Note again that the results are broadly robust to country size and to the magnitude of the adjustment cost parameter and are independent of the detrending method employed to induce stationarity in the data.

Finally, it is interesting to ask whether the assumption that heterogeneity enters the model only through differences in country size has any implications for the qualitative features of the results and for the magnitude of cross country consumption correlations. The additional source of heterogeneity I consider is limited to the parameters of the exogenous forces. Canova and Marrinan (1996) shows that for a more complicated model, existing heterogeneity in the deep parameters is very modest and that results are unaffected by changes of the parameters in the range of the estimates obtained for the US, Canada and Europe. This suggests that the approximation that countries may differ primarily because of their size and exogenous disturbances, instead of their allocative and productive parameters, is somewhat justified.

Allowing for asymmetries in the stochastic processes governing the exogenous shocks does not 
help much in bringing simulated cross country consumption correlations more in line with actual correlations regardless of the size of the countries, the value of the adjustment cost parameter and the detrending method. In all cases considered, the qualitative features of the results remain even though the international consumption correlations generated by a model with asymmetric driving forces are slightly smaller than in the baseline case. Note however that differences relative to the benchmark case presented in table 4 are significant only when $\mu_{g}$ approaches 1 . Note also that this occurs despite the fact that the asymmetries introduced are relatively small.

I have also conducted several other additional sensitivity experiments, varying the taxes rates from 0.3 to 0.5 and to 0.0 , changing the steady state share of government consumption in output from 0.2 to 0.4 and 0.0 , varying the value of $\alpha$ up to 0.75 and decreasing the steady state real rate of interest to $4 \%$ per year. None of these changes produced appreciable changes in the distribution of international private consumption and output correlations from the benchmark cases reported in table 4.

\section{Conclusions}

This paper analyzed whether the introduction of government expenditure shocks in a standard one good international real business cycle model can account for the pattern of international private consumption and output correlations we observe in the real world. The results show that when government expenditure shocks are the only source of business cycle fluctuations and government expenditure enters the utility function of agents and is highly substitutable with private consumption, the model has some potential in explaining, both qualitatively and quantitatively, the observed correlations. However, when both government expenditure and technology disturbances are present, the model can not reproduce the international correlations we see in the data, regardless of how substitutable are government and private consumption in the utility of agents, unless the variability of government expenditure shocks is of an order of magnitude larger than what we see in the data.

I have also tried to identify the parameters which appear to be more important in bringing simulated correlations more in line with actual ones. These are the parameter regulating the sub- 
stitutability between private and public consumption $\mu_{g}$, the variability of government consumption expenditure, the elasticity of the investment capital ratio to changes in Tobin's Q and the parameters regulating the bivariate stochastic process of the technology disturbances across countries. Increasing the first three parameters from their benchmark calibrated values leads to a location shift in the simulated distribution of international consumption and output correlations, while increasing the asymmetries leads to both a location and a dispersion shift. Because some of these parameters are very imprecisely estimated or no measurement exists, the results suggest the need of conducting empirical work aimed at getting a firmer grasp of their magnitude.

Because the scope of the paper was to examine the effect of government consumption disturbances on international private consumption correlations, I did not report the implications of the model for other important business cycle regularities (for this exercise, see in part, Baxter and Crucini (1993) and (1995)). Nor did I address any of the other deficiencies, such as the price puzzle (as described, e.g. in Backus, Kydland and Kehoe (1995)), which are known to exist in international models of the business cycle

Because these exercises are important and may provide a more comprehensive understanding of the properties of the data, they are relegated to future research. 


\section{Data Appendix}

The data used in the study is all taken from Datastream. Consumption measures aggregate private real consumption expenditure on nondurables, durables and services. It is transformed into a per-capita series by dividing the original series by population. Because data on population is annual, quarterly data are obtained by taking the predicted values of an AR(3) regression fitted to a dummy quarterly series, constructed assigning the annual value to each of the four quarters. Government data measures current government expenditure, except in the case of Australia where gross government fixed investment is also included. All data is in real terms. The base year, however, differs across countries. For Australia, Italy, Japan, UK, and West Germany the base is 1985, for France and Switzerland the base is 1980, for Canada the base is 1986 and for the US the base is 1987. All variables are measured in annual rates.

The sample covers the period 1960,1-1991,4 for Australia, Canada, United Kingdom, USA and Germany; the period 1965,1-1991,4 for Japan; the period 1967,1-1991,4 for Switzerland; and the period 1970,1-1991,4 for France and Italy. 


\section{References}

[1] Aiyagari, S.R., Christiano, L. and Eichenbaum, M. (1992), "The Output, Employment and Interest Rate Effects of Government Consumption", Journal of Monetary Economics, 30, 73-86.

[2] Ashauer, D.(1985), "Fiscal Policy and Aggregate Demand?", American Economic Review, 75, 117-127.

[3] Ashauer, D.(1989), "Is Public Expenditure Productive?", Journal of Monetary Economics, 23, 177-200.

[4] Backus, D., Kehoe, P. and Kydland, F. (1992), "International Business Cycles", Journal of Political Economy, 100, 735-775.

[5] Backus, D., Kehoe, P. and Kydland, F. (1995), "International Business Cycles: Theory and Evidence", in T. Cooley (ed.), Frontiers of Business Cycle Research, Princeton University Press.

[6] Barro, R. (1981), "The Output Effects of Government Purchases", Journal of Political Economy, 89, 1086-1121.

[7] Barro, R. (1989), "The Neoclassical Approach to Fiscal Policy", in R. Barro (ed.) Modern Business Cycle Theory, Cambridge, MA: Harvard University Press, 178-235.

[8] Barro,R. and Sala-i-Martin, X. (1992), "Public Finance in Models of Economic Growth", Review of Economic Studies, 59(4), 654-661.

[9] Baxter, M. (1992) "Financial Market Linkages and the International Transmission of Fiscal Policy", University of Rochester, manuscript.

[10] Baxter, M. and Crucini, M. (1993), 'Savings and Investment Correlations", American Economic Review, $83,416-436$.

[11] Baxter, M. and Crucini, M. (1995), "Business Cycle and the Asset Structure of Foreign Trade", forthcoming, International Economic Review.

[12] Baxter, M. and King, R. (1993) "Fiscal Policy in General Equilibrium", American Economic Review, $83,315-334$.

[13] Braun, T. and McGrattan, E. (1993) "The Macroeconomics of War and Peace", NBER Macroeconomic Annual,

[14] Canova, F. (1993) “Detrending and Business Cycle Facts", CEPR, working paper 782.

[15] Canova, F. (1994), "Statistical Inference in Calibrated Models", Journal of Applied Econometrics, 10, S121-S142.

[16] Canova, F. and Marrinan, J. (1996), "Sources and Propagations of International Business Cycles: Common Shocks or Transmission", Universitat Pompeu Fabra, manuscript.

[17] Canova, F. and Ravn, M. (1996), "International Consumption Risk Sharing", International Economic Review, 37,

[18] Cardia, E. (1991), "The Dynamics of a Small Open Economy in Response to Monetary, Fiscal and Productivity Shocks", Journal of Monetary Economics, 28, 411-434.

[19] Christiano, L. and Eichenbaum, M. (1992), "Current Real Business Cycle Theories and Aggregate Labor Market Fluctuations", American Economic Review, 82, 430-450.

[20] Costello, D. (1993), “A Cross Country, Cross Industry Comparison of Productivity Growth", Journal of Political Economy, 101, 207-222.

[21] Deveraux, M., Gregory A., and G. Smith (1992) "Realistic Cross Country Consumption Correlations in a Two Country, Equilibrium, Business Cycle Model", Journal of International Money and Finance, $11,3-16$. 
[22] Dunn, K. and Singleton, K. (1986), "Modelling the Term Structure of Interest Rates Under Nonseparable Utility and Durability of Goods", Journal of Financial Economics, 17, 27-55.

[23] Finn, M. (1991) "Energy Price Shocks, Capacity Utilization and Business Cycle Fluctuations", Empirical Institute, Federal Reserve Bank of Minneapolis, discussion paper 50.

[24] Gregory A., and G. Smith (1991), "Calibration as Testing" Journal of Business and Economic Statistics, 9, 293-303.

[25] Graham, F. (1983), "Fiscal Policy and Aggregate Demand: A Comment", American Economic Review, $83,659-666$.

[26] Head, A. (1992), "Country Size, International Risk Sharing and Business Cycles: Theory and Evidence”, Queen's University manuscript.

[27] King, R., C. Plosser and Rebelo, S. (1988), "Production, Growth and Business Cycles I: The Basic Neoclassical Model", Journal of Monetary Economics, 21, 195-232.

[28] Kollman, R. (1995) , "Consumption, Real Exchange Rates and the Structure of International Asset Markets", Journal of International Money and Finance, 14, 191-211.

[29] Kormendi, R. (1983) , "Government Debt, Government Spending and Private Sector Behavior", American Economic Review, 73, 994-1010.

[30] Mendoza, E. (1991), "Real Business Cycles in a Small Open Economy", American Economic Review, 81(4), 797-818.

[31] Mehra, R. and Prescott, E. (1985), "The Equity Premium: A Puzzle", Journal of Monetary Economics, $15(2), 145-161$.

[32] Persson, T. and Tabellini, G. (1996) "Federal Fiscal Constitution. Part 1:Risk Sharing and Moral Hazard", Econometrica.

[33] Ravn, M. (1993), "International Business Cycles: How Much Can Standard Theory Account For", European University Institute, working paper 9333.

[34] Stockman, A. and Dellas, H. (1989) "International Portfolio Nondiversification and Exchange Rate Variability", Journal of International Economics, 26, 271-289.

[35] Stockman, A. and Tesar, L. (1995), "Tastes and Technology in a Two Country Model of the Business Cycle: Explaining International Comovements", American Economic Review.

[36] Tesar, L. (1993) "International Risk Sharing and Nontraded Goods", Journal of International Economics, 35, 69-90.

[37] Van Wincoop, E. (1993), "Regional Risk Sharing", IGIER manuscript.

[38] Van Wincoop, E. and Marrinan, J. (1996), "Public and Private Savings and Investment", UPF working paper.

[39] Wilcox, J. (1992), "What do we Know about Consumption?", American Economic Review, 82, 929-941. 
Table 1: Estimated Consumption Correlations

\begin{tabular}{|c|c|c|c|c|c|c|c|c|c|c|c|c|}
\hline & AUS & $\mathrm{CAN}$ & FRA & ITA & JAP & SWI & UK & US & WG & MIN & MEDIAN & MAX \\
\hline \multicolumn{13}{|c|}{ Linearly Detrended data } \\
\hline AUS & & $\begin{array}{c}0.767 \\
(0.027)\end{array}$ & $\begin{array}{c}0.387 \\
(0.042)\end{array}$ & $\begin{array}{c}0.246 \\
(0.047)\end{array}$ & $\begin{array}{c}0.809 \\
(0.014)\end{array}$ & $\begin{array}{c}0.154 \\
(0.063)\end{array}$ & $\begin{array}{c}-0.514 \\
(0.041)\end{array}$ & $\begin{array}{c}0.726 \\
(0.038)\end{array}$ & $\begin{array}{c}0.783 \\
(0.223)\end{array}$ & -0.514 & 0.393 & 0.826 \\
\hline $\mathrm{CAN}$ & & & $\begin{array}{c}0.638 \\
(0.044)\end{array}$ & $\begin{array}{c}0.393 \\
(0.047)\end{array}$ & $\begin{array}{c}0.629 \\
(0.035)\end{array}$ & $\begin{array}{c}0.560 \\
(0.056)\end{array}$ & $\begin{array}{l}-0.226 \\
(0.071)\end{array}$ & $\begin{array}{c}0.624 \\
(0.032)\end{array}$ & $\begin{array}{c}0.809 \\
(0.020)\end{array}$ & & & \\
\hline FRA & & & & $\begin{array}{c}0.671 \\
(0.042)\end{array}$ & $\begin{array}{c}0.409 \\
(0.054)\end{array}$ & $\begin{array}{c}0.472 \\
(0.061)\end{array}$ & $\begin{array}{l}-0.184 \\
(0.061)\end{array}$ & $\begin{array}{c}0.292 \\
(0.055)\end{array}$ & $\begin{array}{c}0.586 \\
(0.057)\end{array}$ & & & \\
\hline ITA & & & & & $\begin{array}{c}0.194 \\
(0.023)\end{array}$ & $\begin{array}{c}0.449 \\
(0.050)\end{array}$ & $\begin{array}{c}-0.112 \\
(0.041)\end{array}$ & $\begin{array}{l}-0.103 \\
(0.057)\end{array}$ & $\begin{array}{c}0.274 \\
(0.041)\end{array}$ & & & \\
\hline JAP & & & & & & $\begin{array}{c}0.367 \\
(0.066)\end{array}$ & $\begin{array}{l}-0.225 \\
(0.031)\end{array}$ & $\begin{array}{c}0.443 \\
(0.036)\end{array}$ & $\begin{array}{c}0.826 \\
(0.015)\end{array}$ & & & \\
\hline SWI & & & & & & & $\begin{array}{c}0.232 \\
(0.064)\end{array}$ & $\begin{array}{c}0.426 \\
(0.052)\end{array}$ & $\begin{array}{c}0.383 \\
(0.053)\end{array}$ & & & \\
\hline UK & & & & & & & & $\begin{array}{l}-0.113 \\
(0.059)\end{array}$ & $\begin{array}{c}-0.331 \\
(0.044)\end{array}$ & & & \\
\hline US & & & & & & & & & $\begin{array}{c}0.551 \\
(0.035)\end{array}$ & & & \\
\hline \multicolumn{13}{|c|}{ HP Filtered data } \\
\hline AUS & & $\begin{array}{c}0.217 \\
(0.065)\end{array}$ & $\begin{array}{c}0.237 \\
(0.083)\end{array}$ & $\begin{array}{c}0.250 \\
(0.087)\end{array}$ & $\begin{array}{c}0.232 \\
(0.072)\end{array}$ & $\begin{array}{c}0.024 \\
(0.083)\end{array}$ & $\begin{array}{c}0.115 \\
(0.061)\end{array}$ & $\begin{array}{c}0.047 \\
(0.067)\end{array}$ & $\begin{array}{c}-0.194 \\
(0.068)\end{array}$ & -0.194 & 0.287 & 0.607 \\
\hline $\mathrm{CAN}$ & & & $\begin{array}{c}0.401 \\
(0.069)\end{array}$ & $\begin{array}{c}0.244 \\
(0.051)\end{array}$ & $\begin{array}{c}0.039 \\
(0.058)\end{array}$ & $\begin{array}{c}0.455 \\
(0.059)\end{array}$ & $\begin{array}{c}0.392 \\
(0.049)\end{array}$ & $\begin{array}{c}0.607 \\
(0.041)\end{array}$ & $\begin{array}{c}0.060 \\
(0.071)\end{array}$ & & & \\
\hline FRA & & & & $\begin{array}{c}0.172 \\
(0.075)\end{array}$ & $\begin{array}{c}0.428 \\
(0.061)\end{array}$ & $\begin{array}{c}0.439 \\
(0.091)\end{array}$ & $\begin{array}{c}0.508 \\
(0.054)\end{array}$ & $\begin{array}{c}0.580 \\
(0.090)\end{array}$ & $\begin{array}{c}0.258 \\
(0.097)\end{array}$ & & & \\
\hline ITA & & & & & $\begin{array}{c}0.317 \\
(0.068)\end{array}$ & $\begin{array}{c}0.468 \\
(0.058)\end{array}$ & $\begin{array}{c}0.395 \\
(0.056)\end{array}$ & $\begin{array}{c}0.060 \\
(0.080)\end{array}$ & $\begin{array}{c}0.205 \\
(0.096)\end{array}$ & & & \\
\hline JAP & & & & & & $\begin{array}{c}0.287 \\
(0.080)\end{array}$ & $\begin{array}{c}0.552 \\
(0.065)\end{array}$ & $\begin{array}{c}0.408 \\
(0.065)\end{array}$ & $\begin{array}{c}0.229 \\
(0.080)\end{array}$ & & & \\
\hline SWI & & & & & & & $\begin{array}{c}0.429 \\
(0.053)\end{array}$ & $\begin{array}{c}0.451 \\
(0.059)\end{array}$ & $\begin{array}{c}0.511 \\
(0.061)\end{array}$ & & & \\
\hline UK & & & & & & & & $\begin{array}{c}0.366 \\
(0.058)\end{array}$ & $\begin{array}{c}0.125 \\
(0.080)\end{array}$ & & & \\
\hline US & & & & & & & & & $\begin{array}{c}0.340 \\
(0.074)\end{array}$ & & & \\
\hline \multicolumn{13}{|c|}{ FOD Filtered data } \\
\hline AUS & & $\begin{array}{c}0.419 \\
(0.068)\end{array}$ & $\begin{array}{c}0.403 \\
(0.068)\end{array}$ & $\begin{array}{c}0.070 \\
(0.097)\end{array}$ & $\begin{array}{c}0.251 \\
(0.073)\end{array}$ & $\begin{array}{c}0.269 \\
(0.093)\end{array}$ & $\begin{array}{c}0.046 \\
(0.078)\end{array}$ & $\begin{array}{c}0.313 \\
(0.066)\end{array}$ & $\begin{array}{c}0.070 \\
(0.066)\end{array}$ & -0.038 & 0.154 & 0.531 \\
\hline $\mathrm{CAN}$ & & & $\begin{array}{c}0.297 \\
(0.068)\end{array}$ & $\begin{array}{c}0.133 \\
(0.112)\end{array}$ & $\begin{array}{c}0.071 \\
(0.068)\end{array}$ & $\begin{array}{c}0.344 \\
(0.103)\end{array}$ & $\begin{array}{c}0.089 \\
(0.080)\end{array}$ & $\begin{array}{c}0.531 \\
(0.059)\end{array}$ & $\begin{array}{c}0.133 \\
(0.066)\end{array}$ & & & \\
\hline FRA & & & & $\begin{array}{c}0.065 \\
(0.071)\end{array}$ & $\begin{array}{c}0.299 \\
(0.068)\end{array}$ & $\begin{array}{c}0.355 \\
(0.073)\end{array}$ & $\begin{array}{c}0.169 \\
(0.092)\end{array}$ & $\begin{array}{c}0.162 \\
(0.057)\end{array}$ & $\begin{array}{c}0.305 \\
(0.064)\end{array}$ & & & \\
\hline ITA & & & & & $\begin{array}{c}0.090 \\
(0.094)\end{array}$ & $\begin{array}{c}0.355 \\
(0.118)\end{array}$ & $\begin{array}{c}0.094 \\
(0.078)\end{array}$ & $\begin{array}{c}-0.038 \\
(0.101)\end{array}$ & $\begin{array}{c}0.048 \\
(0.098)\end{array}$ & & & \\
\hline JAP & & & & & & $\begin{array}{c}0.035 \\
(0.068)\end{array}$ & $\begin{array}{c}0.077 \\
(0.048)\end{array}$ & $\begin{array}{c}0.267 \\
(0.046)\end{array}$ & $\begin{array}{c}0.091 \\
(0.053)\end{array}$ & & & \\
\hline SWI & & & & & & & $\begin{array}{c}0.154 \\
(0.061)\end{array}$ & $\begin{array}{c}0.172 \\
(0.084)\end{array}$ & $\begin{array}{c}0.122 \\
(0.053)\end{array}$ & & & \\
\hline UK & & & & & & & & $\begin{array}{c}0.189 \\
(0.057)\end{array}$ & $\begin{array}{c}0.149 \\
(0.068)\end{array}$ & & & \\
\hline US & & & & & & & & & $\begin{array}{c}0.233 \\
(0.077)\end{array}$ & & & \\
\hline
\end{tabular}

Notes: Standard errors are in parenthesis. 
Table 2: Estimated Output Correlations

\begin{tabular}{|c|c|c|c|c|c|c|c|c|c|c|c|c|}
\hline & AUS & $\mathrm{CAN}$ & FRA & ITA & $\mathrm{JAP}$ & SWI & UK & US & WG & MIN & MEDIAN & MAX \\
\hline \multicolumn{13}{|c|}{ Linearly Detrended data } \\
\hline \multirow[t]{2}{*}{ AUS } & & 0.840 & 0.288 & 0.150 & 0.752 & 0.298 & 0.452 & 0.817 & 0.628 & -0.094 & 0.361 & 0.840 \\
\hline & & $(0.022)$ & $(0.057)$ & $(0.046)$ & $(0.023)$ & $(0.085)$ & $(0.050)$ & $(0.032)$ & $(0.034)$ & & & \\
\hline \multirow[t]{2}{*}{$\mathrm{CAN}$} & & & 0.449 & 0.373 & 0.429 & -0.063 & 0.398 & 0.743 & 0.667 & & & \\
\hline & & & $(0.037)$ & $(0.031)$ & $(0.032)$ & $(0.073)$ & $(0.061)$ & $(0.033)$ & $(0.030)$ & & & \\
\hline \multirow[t]{2}{*}{ FRA } & & & & 0.794 & 0.295 & -0.094 & 0.345 & 0.361 & 0.611 & & & \\
\hline & & & & $(0.029)$ & $(0.058)$ & $(0.071)$ & $(0.062)$ & $(0.066)$ & $(0.063)$ & & & \\
\hline \multirow[t]{2}{*}{ ITA } & & & & & 0.095 & 0.065 & 0.074 & 0.214 & 0.429 & & & \\
\hline & & & & & $(0.032)$ & $(0.055)$ & $(0.074)$ & $(0.066)$ & $(0.047)$ & & & \\
\hline \multirow[t]{2}{*}{ JAP } & & & & & & 0.253 & 0.145 & 0.225 & 0.769 & & & \\
\hline & & & & & & $(0.077)$ & $(0.036)$ & $(0.048)$ & $(0.021)$ & & & \\
\hline \multirow[t]{2}{*}{ SWI } & & & & & & & 0.567 & 0.336 & 0.029 & & & \\
\hline & & & & & & & $(0.060)$ & $(0.088)$ & $(0.096)$ & & & \\
\hline \multirow[t]{2}{*}{ UK } & & & & & & & & 0.608 & 0.286 & & & \\
\hline & & & & & & & & $(0.038)$ & $(0.059)$ & & & \\
\hline \multirow[t]{2}{*}{ US } & & & & & & & & & 0.435 & & & \\
\hline & & & & & & & & & $(0.038)$ & & & \\
\hline \multirow{3}{*}{ AUS } & & & & & & Filtere & d data & & & & & \\
\hline & & 0.514 & 0.326 & 0.463 & 0.412 & 0.424 & 0.340 & 0.389 & 0.346 & 0.165 & 0.412 & 0.789 \\
\hline & & $(0.061)$ & $(0.051)$ & $(0.051)$ & $(0.036)$ & $(0.058)$ & $(0.050)$ & $(0.062)$ & $(0.051)$ & & & \\
\hline \multirow[t]{2}{*}{$\mathrm{CAN}$} & & & 0.444 & 0.354 & 0.165 & 0.425 & 0.460 & 0.744 & 0.322 & & & \\
\hline & & & $(0.047)$ & $(0.048)$ & $(0.053)$ & $(0.040)$ & $(0.045)$ & $(0.027)$ & $(0.062)$ & & & \\
\hline \multirow[t]{2}{*}{ FRA } & & & & 0.588 & 0.511 & 0.536 & 0.655 & 0.596 & 0.488 & & & \\
\hline & & & & $(0.065)$ & $(0.061)$ & $(0.066)$ & $(0.051)$ & $(0.074)$ & $(0.080)$ & & & \\
\hline \multirow[t]{2}{*}{ ITA } & & & & & 0.324 & 0.789 & 0.308 & 0.334 & 0.496 & & & \\
\hline & & & & & $(0.086)$ & $(0.045)$ & $(0.075)$ & $(0.058)$ & $(0.051)$ & & & \\
\hline \multirow[t]{2}{*}{ JAP } & & & & & & 0.377 & 0.310 & 0.330 & 0.645 & & & \\
\hline & & & & & & $(0.061)$ & $(0.081)$ & $(0.085)$ & $(0.042)$ & & & \\
\hline \multirow[t]{2}{*}{ SWI } & & & & & & & 0.209 & 0.395 & 0.407 & & & \\
\hline & & & & & & & $(0.071)$ & $(0.053)$ & $(0.053)$ & & & \\
\hline \multirow[t]{2}{*}{ UK } & & & & & & & & 0.595 & 0.366 & & & \\
\hline & & & & & & & & $(0.049)$ & $(0.060)$ & & & \\
\hline \multirow[t]{2}{*}{ US } & & & & & & & & & 0.419 & & & \\
\hline & & & & & & & & & $(0.078)$ & & & \\
\hline & & & & & $\mathrm{FO}$ & D Filter & d data & & & & & \\
\hline AUS & & 0.338 & 0.149 & 0.198 & 0.231 & 0.176 & 0.174 & 0.282 & -0.014 & -0.053 & 0.206 & 0.566 \\
\hline & & $(0.067)$ & $(0.083)$ & $(0.090)$ & $(0.054)$ & $(0.077)$ & $(0.069)$ & $(0.075)$ & $(0.083)$ & & & \\
\hline $\mathrm{CAN}$ & & & 0.264 & 0.090 & 0.238 & 0.135 & 0.145 & 0.566 & 0.158 & & & \\
\hline & & & $(0.077)$ & $(0.082)$ & $(0.067)$ & $(0.073)$ & $(0.082)$ & $(0.053)$ & $(0.063)$ & & & \\
\hline FRA & & & & 0.554 & 0.247 & 0.300 & 0.231 & 0.393 & 0.387 & & & \\
\hline & & & & $(0.059)$ & $(0.104)$ & $(0.078)$ & $(0.070)$ & $(0.080)$ & $(0.060)$ & & & \\
\hline ITA & & & & & 0.114 & 0.490 & 0.061 & 0.206 & 0.295 & & & \\
\hline & & & & & $(0.056)$ & $(0.070)$ & $(0.065)$ & $(0.061)$ & $(0.062)$ & & & \\
\hline $\mathrm{JAP}$ & & & & & & -0.053 & 0.247 & 0.251 & 0.150 & & & \\
\hline & & & & & & $(0.091)$ & $(0.058)$ & $(0.071)$ & $(0.065)$ & & & \\
\hline SWI & & & & & & & 0.063 & 0.342 & 0.145 & & & \\
\hline & & & & & & & $(0.061)$ & $(0.083)$ & $(0.069)$ & & & \\
\hline UK & & & & & & & & 0.182 & 0.275 & & & \\
\hline & & & & & & & & $(0.080)$ & $(0.082)$ & & & \\
\hline US & & & & & & & & & 0.144 & & & \\
\hline & & & & & & & & & $(0.066)$ & & & \\
\hline
\end{tabular}

Notes: Standard errors are in parenthesis. 
Table 3: Calibrated Values for the Parameters Basic Simulations

\begin{tabular}{lcc}
\hline \hline & US-Canada & US-Europe \\
\hline \hline Labour augmenting technological progress: $\gamma_{x}$ & 1.004 & 1.004 \\
Steady state G/Y share: $s_{g}$ & 0.20 & 0.20 \\
Tax rate: $\tau$ & 0.30 & 0.30 \\
Steady state hours: $\bar{N}$ & 0.2 & 0.2 \\
Steady state interest rate: $R$ & 0.065 & 0.065 \\
Labor share in production: $1-\alpha$ & 0.58 & 0.60 \\
Elasticity of I/K to Tobin's Q: $\xi$ & -0.075 & -0.075 \\
SS Tobin's Q: $S S T$ & 1.0 & 1.0 \\
Depreciation rate: $\delta$ & 0.025 & 0.025 \\
CRRA parameter: $\sigma$ & 2.0 & 2.0 \\
Population share: $\pi$ & 0.9 & 0.5 \\
Substitutability parameter: $\mu_{g}$ & 0.0 & 0.0 \\
& 0.2 & 0.2 \\
& 0.5 & 0.5 \\
\hline \hline
\end{tabular}

\begin{tabular}{ccccc}
\hline \hline & US & Canada & US & Europe \\
\hline \hline \multicolumn{5}{c}{ Technology shocks } \\
$\Omega$ & 0.866 & 0.02 & 0.904 & 0.052 \\
$\Omega$ & 0.04 & 0.929 & 0.149 & 0.908 \\
& 0.00061 & 0.00023 & 0.00082 & 0.00018 \\
& 0.00023 & 0.00071 & 0.00018 & 0.00063 \\
& \multicolumn{5}{c}{ Government shocks } \\
$\rho$ & 0.95 & 0.0 & 0.95 & 0.0 \\
$\Omega$ & 0.0 & 0.95 & 0.0 & 0.90 \\
$\Omega$ & 0.00016 & 0.0 & 0.00016 & 0.0 \\
& 0.0 & 0.00016 & 0.0 & 0.00010 \\
& \multicolumn{5}{c}{ Symmetric technology shocks } \\
$\rho$ & 0.898 & 0.043 & 0.906 & 0.088 \\
& 0.043 & 0.898 & 0.088 & 0.906 \\
$\Omega$ & 0.00064 & 0.00016 & 0.00072 & 0.00018 \\
& 0.00016 & 0.00064 & 0.00018 & 0.00072 \\
\hline \hline
\end{tabular}


Table 4: Basic Simulations

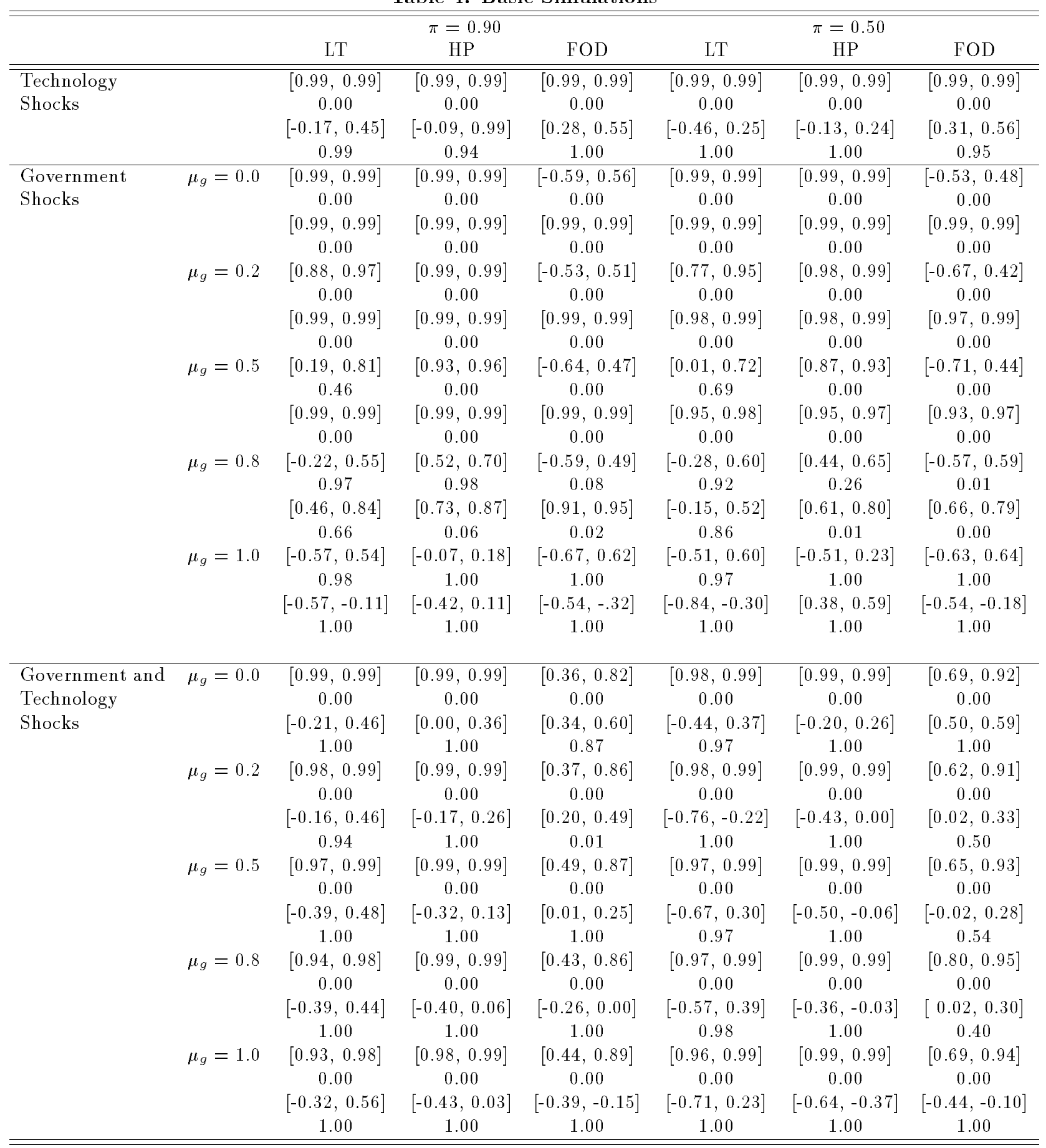

Notes: The first (third) row of each simulation reports the $90 \%$ range of the simulated cross country consumption (output) distribution, the second (fourth) the probability that the model generates the value we observe in the actual data. 
Table 5.1: Sensitivity Analysis

\begin{tabular}{|c|c|c|c|c|c|c|c|}
\hline & & & $\pi=0.90$ & & & $\pi=0.50$ & \\
\hline & & $\mathrm{LT}$ & HP & FOD & LT & HP & FOD \\
\hline & & & $\xi=$ & -0.01 & & & \\
\hline Technology & & {$[0.91,0.97]$} & {$[0.98,0.99]$} & {$[0.94,0.97]$} & {$[0.94,0.98]$} & {$[0.99,0.99]$} & {$[0.96,0.98]$} \\
\hline Shocks & & 0.00 & 0.00 & 0.00 & 0.00 & 0.00 & 0.00 \\
\hline & & {$[-0.29,-0.45]$} & {$[-0.73,-0.45]$} & {$[-0.28,-0.02]$} & {$[-0.85,0.49]$} & {$[-0.77,-0.54]$} & {$[-0.23,0.10]$} \\
\hline & & 1.00 & 1.00 & 1.00 & 1.00 & 1.00 & 1.00 \\
\hline Government and & $\mu_{g}=0.0$ & {$[0.99,0.99]$} & {$[0.99,0.99]$} & {$[-0.53,0.54]$} & {$[0.99,0.99]$} & {$[0.99,0.99]$} & {$[-0.55,0.54]$} \\
\hline Shocks & & 0.00 & 0.00 & 0.00 & 0.00 & 0.00 & 0.00 \\
\hline & & {$[0.99,0.99]$} & {$[0.99,0.99]$} & {$[0.99,0.99]$} & {$[0.99,0.99]$} & {$[0.99,0.99]$} & {$[0.99,0.99]$} \\
\hline & & 0.00 & 0.00 & 0.00 & 0.00 & 0.00 & 0.00 \\
\hline & $\mu_{g}=0.2$ & {$[0.87,0.97]$} & {$[0.94,0.99]$} & {$[-0.64,0.49]$} & {$[0.78,0.96]$} & {$[0.98,0.99]$} & {$[-0.68,0.56]$} \\
\hline & & 0.00 & 0.00 & 0.00 & 0.00 & 0.00 & 0.00 \\
\hline & & {$[0.99,0.99]$} & {$[0.99,0.99]$} & {$[0.99,0.99]$} & {$[0.98,0.99]$} & {$[0.98,0.99]$} & {$[0.97,0.98]$} \\
\hline & & 0.00 & 0.00 & 0.00 & 0.00 & 0.00 & 0.00 \\
\hline & $\mu_{g}=0.5$ & {$[0.12,0.77]$} & {$[0.91,0.95]$} & {$[-0.67,0.48]$} & {$[0.07,0.78]$} & {$[0.86,0.93]$} & {$[-0.66,0.55]$} \\
\hline & & 0.61 & 0.00 & 0.00 & 0.50 & 0.00 & 0.00 \\
\hline & & {$[0.97,0.99]$} & {$[0.99,0.99]$} & {$[0.99,0.99]$} & {$[0.90,0.97]$} & {$[0.94,0.96]$} & {$[0.93,0.96]$} \\
\hline & & 0.00 & 0.00 & 0.00 & 0.00 & 0.00 & 0.00 \\
\hline & $\mu_{g}=0.8$ & {$[-0.28,0.56]$} & {$[0.54,0.68]$} & {$[-0.61,0.55]$} & {$[-0.20,0.53]$} & {$[0.43,0.66]$} & {$[-0.58,0.47]$} \\
\hline & & 0.92 & 0.90 & 0.05 & 0.94 & 0.31 & 0.23 \\
\hline & & {$[0.80,0.92]$} & {$[0.95,0.97]$} & {$[0.97,0.98]$} & {$[0.39,0.81]$} & {$[0.82,0.88]$} & {$[0.71,0.84]$} \\
\hline & & 0.06 & 0.02 & 0.04 & 0.05 & 0.04 & 0.01 \\
\hline & $\mu_{g}=1.0$ & {$[-0.58,0.60]$} & {$[-0.09,0.26]$} & {$[-0.64,0.66]$} & {$[-0.49,0.55]$} & {$[-0.08,0.22]$} & {$[-0.65,0.62]$} \\
\hline & & 0.96 & 1.00 & 1.00 & 0.94 & 0.85 & 0.96 \\
\hline & & {$[-0.96,-0.60]$} & {$[-0.74,-0.38]$} & {$[-0.76,-.58]$} & {$[-0.96,-0.80]$} & {$[0.07,0.35]$} & {$[-0.63,-0.40]$} \\
\hline & & 1.00 & 1.00 & 1.00 & 1.00 & 1.00 & 1.00 \\
\hline Government and & $\mu_{g}=0.0$ & {$[0.90,0.97]$} & {$[0.98,0.99]$} & {$[0.33,0.81]$} & {$[0.94,0.98]$} & {$[0.99,0.99]$} & {$[0.63,0.91]$} \\
\hline Technology & & 0.00 & 0.00 & 0.00 & 0.00 & 0.00 & 0.00 \\
\hline Shocks & & {$[-0.80,-0.33]$} & {$[-0.66,-0.31]$} & {$[0.23,0.07]$} & {$[-0.85,-0.42]$} & {$[-0.79,-0.52]$} & {$[-0.22,0.11]$} \\
\hline & & 1.00 & 1.00 & 0.98 & 1.00 & 1.00 & 0.97 \\
\hline & $\mu_{g}=0.2$ & {$[0.90,0.97]$} & {$[0.98,0.99]$} & {$[0.38,0.88]$} & {$[0.92,0.98]$} & {$[0.98,0.99]$} & {$[0.51,0.88]$} \\
\hline & & 0.00 & 0.00 & 0.00 & 0.00 & 0.00 & 0.00 \\
\hline & & {$[-0.85,0.26]$} & {$[-0.75,-0.46]$} & {$[-0.35,-0.06]$} & {$[-0.53,-0.88]$} & {$[-0.89,-0.73]$} & {$[-0.58,-0.31]$} \\
\hline & & 1.00 & 1.00 & 1.00 & 1.00 & 1.00 & 1.00 \\
\hline & $\mu_{g}=0.5$ & {$[0.85,0.97]$} & {$[0.98,0.99]$} & {$[0.37,0.85]$} & {$[0.93,0.98]$} & {$[0.99,0.99]$} & {$[0.62,0.91]$} \\
\hline & & 0.00 & 0.00 & 0.00 & 0.00 & 0.00 & 0.00 \\
\hline & & {$[-0.85,-0.32]$} & {$[-0.80,-0.50]$} & {$[-0.55,-0.28]$} & {$[-0.80,-0.27]$} & {$[-0.86,-0.67]$} & {$[-0.50,-0.24]$} \\
\hline & & 1.00 & 1.00 & 1.00 & 0.97 & 1.00 & 1.00 \\
\hline & $\mu_{g}=0.8$ & {$[0.84,0.96]$} & {$[0.98,0.98]$} & {$[0.39,0.85]$} & {$[0.93,0.98]$} & {$[0.99,0.99]$} & {$[0.71,0.92]$} \\
\hline & & 0.00 & 0.00 & 0.00 & 0.00 & 0.00 & 0.00 \\
\hline & & {$[-0.82,0.25]$} & {$[-0.85,-0.59]$} & {$[-0.66,-0.29]$} & {$[-0.83,-0.25]$} & {$[-0.87,-0.72]$} & {$[-0.65,-0.32]$} \\
\hline & & 1.00 & 1.00 & 1.00 & 1.00 & 1.00 & 1.00 \\
\hline & $\mu_{g}=1.0$ & {$[0.84,0.96]$} & {$[0.97,0.98]$} & {$[0.40,0.88]$} & {$[0.90,0.98]$} & {$[0.98,0.99]$} & {$[0.69,0.93]$} \\
\hline & & 0.00 & 0.00 & 0.00 & 0.00 & 0.00 & 0.00 \\
\hline & & {$[-0.85,-0.25]$} & {$[-0.86,-0.60]$} & {$[-0.73,-0.57]$} & {$[-0.89,-0.20]$} & {$[-0.92,-0.80]$} & {$[-0.76,-0.57]$} \\
\hline & & 1.00 & 1.00 & 1.00 & 1.00 & 1.00 & 1.00 \\
\hline
\end{tabular}

Notes: The first (third) row of each simulation reports the $90 \%$ range of the simulated cross country consumption (output) distribution, the second (fourth) the probability that the model generates the value we observe in the actual data. 
Table 5.2: Sensitivity Analysis

\begin{tabular}{|c|c|c|c|c|c|c|c|}
\hline & & \multicolumn{3}{|c|}{$\pi=0.90$} & \multicolumn{3}{|c|}{$\pi=0.50$} \\
\hline & & LT & HP & FOD & LT & HP & FOD \\
\hline \multicolumn{8}{|c|}{$\gamma=10$} \\
\hline \multirow{4}{*}{$\begin{array}{l}\text { Technology } \\
\text { Shocks }\end{array}$} & & {$[0.97,0.99]$} & {$[0.98,0.99]$} & {$[0.98,0.99]$} & {$[0.99,0.99]$} & {$[0.99,0.99]$} & {$[0.99,0.99]$} \\
\hline & & 0.00 & 0.00 & 0.00 & 0.00 & 0.00 & 0.00 \\
\hline & & {$[0.30,0.70]$} & {$[0.52,0.77]$} & {$[0.77,0.87]$} & {$[0.77,0.89]$} & {$[0.81,0.90]$} & {$[0.91,0.95]$} \\
\hline & & 0.98 & 0.89 & 0.00 & 0.02 & 0.00 & 0.00 \\
\hline \multirow{20}{*}{$\begin{array}{l}\text { Government } \\
\text { Shocks }\end{array}$} & $\mu_{g}=0.0$ & {$[0.99,0.99]$} & {$[0.99,0.99]$} & {$[-0.58,0.49]$} & {$[0.99,0.99]$} & {$[0.99,0.99]$} & {$[-0.64,0.51]$} \\
\hline & & 0.00 & 0.00 & 0.00 & 0.00 & 0.00 & 0.00 \\
\hline & & {$[0.99,0.99]$} & {$[0.99,0.99]$} & {$[0.99,0.99]$} & {$[0.99,0.99]$} & {$[0.99,0.99]$} & {$[0.99,0.99]$} \\
\hline & & 0.00 & 0.00 & 0.00 & 0.00 & 0.00 & 0.00 \\
\hline & $\mu_{g}=0.2$ & {$[0.89,0.98]$} & {$[0.94,0.99]$} & {$[-0.61,0.53]$} & {$[0.81,0.97]$} & {$[0.98,0.99]$} & {$[-0.68,0.48]$} \\
\hline & & 0.00 & 0.00 & 0.00 & 0.00 & 0.00 & 0.00 \\
\hline & & {$[0.99,0.99]$} & {$[0.99,0.99]$} & {$[0.98,0.99]$} & {$[0.98,0.99]$} & {$[0.98,0.99]$} & {$[0.93,0.98]$} \\
\hline & & 0.00 & 0.00 & 0.00 & 0.00 & 0.00 & 0.00 \\
\hline & $\mu_{g}=0.5$ & {$[0.35,0.88]$} & {$[0.94,0.97]$} & {$[-0.61,0.62]$} & {$[0.33,0.83]$} & {$[0.91,0.95]$} & {$[-0.60,0.45]$} \\
\hline & & 0.25 & 0.00 & 0.00 & 0.33 & 0.00 & 0.00 \\
\hline & & {$[0.63,0.93]$} & {$[0.91,0.95]$} & {$[0.93,0.96]$} & {$[0.21,0.85]$} & {$[0.83,0.91]$} & {$[0.87,0.93]$} \\
\hline & & 0.14 & 0.00 & 0.00 & 0.25 & 0.00 & 0.00 \\
\hline & $\mu_{g}=0.8$ & {$[0.12,0.75]$} & {$[0.82,0.93]$} & {$[-0.59,0.54]$} & {$[0.03,0.64]$} & {$[0.78,0.86]$} & {$[-0.57,0.52]$} \\
\hline & & 0.84 & 0.87 & 0.11 & 0.86 & 0.35 & 0.02 \\
\hline & & {$[0.40,0.82]$} & {$[0.57,0.72]$} & {$[0.71,0.85]$} & {$[0.10,0.82]$} & {$[0.68,0.83]$} & {$[0.60,0.76]$} \\
\hline & & 0.64 & 0.10 & 0.03 & 0.79 & 0.03 & 0.02 \\
\hline & $\mu_{g}=1.0$ & {$[-0.08,0.73]$} & {$[0.74,0.85]$} & {$[-0.55,0.70]$} & {$[-0.05,0.71]$} & {$[0.63,0.78]$} & {$[-0.56,0.73]$} \\
\hline & & 0.77 & 0.15 & 0.00 & 0.78 & 0.01 & 0.00 \\
\hline & & {$[-0.68,0.34]$} & {$[-0.32,0.15]$} & {$[-0.55,0.70]$} & {$[-0.05,0.71]$} & {$[0.63,0.78]$} & {$[-0.56,0.73]$} \\
\hline & & 1.00 & 1.00 & 1.00 & 0.99 & 1.00 & 0.96 \\
\hline \multirow{20}{*}{$\begin{array}{l}\text { Government and } \\
\text { Technology } \\
\text { Shocks }\end{array}$} & $\mu_{g}=0.0$ & {$[0.92,0.98]$} & {$[0.89,0.93]$} & {$[0.72,0.93]$} & {$[0.99,0.99]$} & {$[0.99,0.99]$} & {$[0.90,0.97]$} \\
\hline & & 0.00 & 0.00 & 0.00 & 0.00 & 0.00 & 0.00 \\
\hline & & {$[0.28,0.83]$} & {$[0.15,0.60]$} & {$[0.16,0.46]$} & {$[0.77,0.89]$} & {$[0.81,0.90]$} & {$[0.90,0.95]$} \\
\hline & & 0.79 & 1.00 & 1.00 & 0.00 & 0.00 & 0.00 \\
\hline & $\mu_{g}=0.2$ & {$[0.97,0.99]$} & {$[0.99,0.90]$} & {$[0.84,0.96]$} & {$[0.97,0.99]$} & {$[0.98,0.99]$} & {$[0.79,0.95]$} \\
\hline & & 0.00 & 0.00 & 0.00 & 0.00 & 0.00 & 0.00 \\
\hline & & {$[0.25,0.69]$} & {$[0.37,0.68]$} & {$[0.66,0.82]$} & {$[0.08,0.59]$} & {$[0.13,0.49]$} & {$[0.43,0.69]$} \\
\hline & & 1.00 & 0.90 & 0.00 & 0.72 & 0.78 & 0.00 \\
\hline & $\mu_{g}=0.5$ & {$[0.97,0.99]$} & {$[0.99,0.99]$} & {$[0.90,0.97]$} & {$[0.90,0.99]$} & {$[0.99,0.99]$} & {$[0.96,0.99]$} \\
\hline & & 0.00 & 0.00 & 0.00 & 0.00 & 0.00 & 0.00 \\
\hline & & {$[-0.02,-0.39]$} & {$[0.80,0.35]$} & {$[0.32,0.57]$} & {$[0.14,0.55]$} & {$[0.39,0.67]$} & {$[0.67,0.88]$} \\
\hline & & 0.96 & 1.00 & 0.00 & 0.68 & 0.09 & 0.00 \\
\hline & $\mu_{g}=0.8$ & {$[0.92,0.98]$} & {$[0.99,0.99]$} & {$[0.92,0.97]$} & {$[0.93,0.98]$} & {$[0.99,0.99]$} & {$[0.96,0.99]$} \\
\hline & & 0.00 & 0.00 & 0.00 & 0.00 & 0.00 & 0.00 \\
\hline & & {$[-0.38,0.01]$} & {$[0.14,0.34]$} & {$[0.19,0.39]$} & {$[-0.18,0.15]$} & {$[0.15,0.27]$} & {$[0.05,0.31]$} \\
\hline & & 1.00 & 1.00 & 1.00 & 1.00 & 1.00 & 1.00 \\
\hline & $\mu_{g}=1.0$ & {$[0.88,0.98]$} & {$[0.99,0.99]$} & {$[0.95,0.98]$} & {$[0.94,0.98]$} & {$[0.99,0.99]$} & {$[0.97,0.99]$} \\
\hline & & 0.00 & 0.00 & 0.00 & 0.00 & 0.00 & 0.00 \\
\hline & & {$[-0.51,0.44]$} & {$[-0.22,0.23]$} & {$[0.08,0.36]$} & {$[-0.51,-0.57]$} & {$[-0.57,-0.12]$} & {$[-0.04,0.29]$} \\
\hline & & 0.94 & 1.00 & 0.16 & 1.00 & 1.00 & 0.58 \\
\hline
\end{tabular}

Notes: The first (third) row of each simulation reports the $90 \%$ range of the simulated cross country consumption (output) distribution, the second (fourth) the probability that the model generates the value we observe in the actual data. 
Table 5.3: Sensitivity Analysis

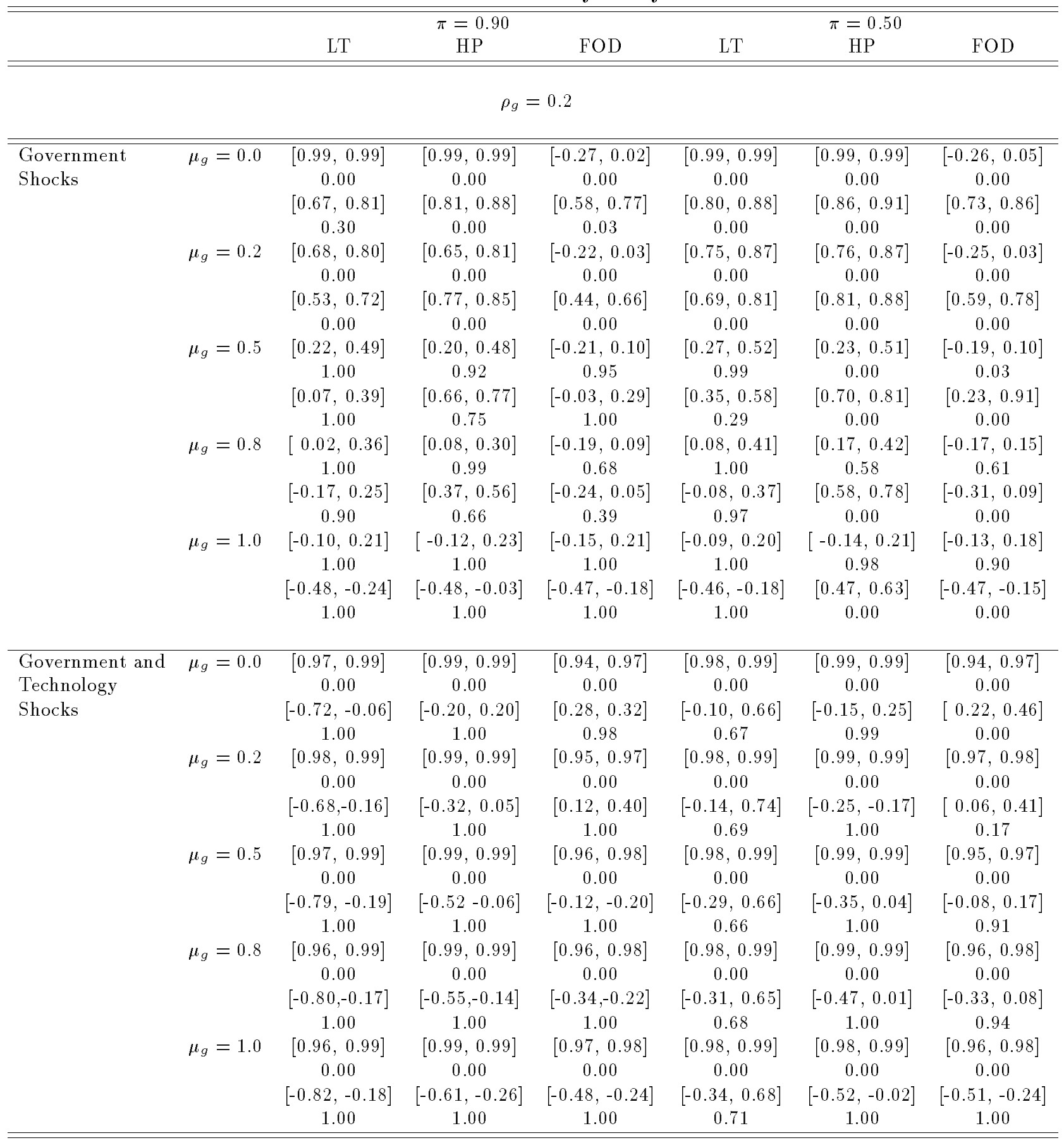

Notes: The first (third) row of each simulation reports the $90 \%$ range of the simulated cross country consumption (output) distribution, the second (fourth) the probability that the model generates the value we observe in the actual data. 
Table 5.4: Sensitivity Analysis

\begin{tabular}{|c|c|c|c|c|c|c|c|}
\hline & & \multicolumn{3}{|c|}{$\pi=0.90$} & \multicolumn{3}{|c|}{$\pi=0.50$} \\
\hline & & LT & HP & FOD & LT & HP & FOD \\
\hline \multicolumn{8}{|c|}{ var $g_{t}=0.0064$} \\
\hline Government and & $\mu_{g}=0.0$ & {$[0.99,0.99]$} & {$[0.99,0.99]$} & {$[-0.45,0.51]$} & {$[0.99,0.99]$} & {$[0.99,0.99]$} & {$[-0.53,0.59]$} \\
\hline Technology & & 0.00 & 0.00 & 0.00 & 0.00 & 0.00 & 0.00 \\
\hline \multirow[t]{18}{*}{ Shocks } & & {$[0.52,0.83]$} & {$[0.67,0.84]$} & {$[0.84,0.92]$} & {$[0.21,0.72]$} & {$[0.48,0.74]$} & {$[0.76,0.86]$} \\
\hline & & 0.58 & 0.32 & 0.00 & 0.38 & 0.00 & 0.00 \\
\hline & $\mu_{g}=0.2$ & {$[0.91,0.98]$} & {$[0.99,0.99]$} & {$[-0.51,0.52]$} & {$[0.92,0.98]$} & {$[0.99,0.99]$} & {$[-0.51,0.47]$} \\
\hline & & 0.00 & 0.00 & 0.00 & 0.00 & 0.00 & 0.00 \\
\hline & & {$[0.40,0.79]$} & {$[0.54,0.77]$} & {$[0.78,0.88]$} & {$[-0.06,0.56]$} & {$[0.24,0.61]$} & {$[0.66,0.80]$} \\
\hline & & 0.89 & 0.90 & 0.00 & 0.75 & 0.29 & 0.00 \\
\hline & $\mu_{g}=0.5$ & {$[0.59,0.92]$} & {$[0.95,0.97]$} & {$[-0.49,0.54]$} & {$[0.67,0.94]$} & {$[0.96,0.97]$} & {$[-0.60,0.60]$} \\
\hline & & 0.06 & 0.00 & 0.00 & 0.01 & 0.00 & 0.00 \\
\hline & & {$[0.02,0.66]$} & {$[0.18,0.53]$} & {$[0.54,0.73]$} & {$[-0.32,0.48]$} & {$[-0.02,0.37]$} & {$[0.40,0.63]$} \\
\hline & & 0.99 & 1.00 & 0.12 & 0.93 & 0.96 & 0.00 \\
\hline & $\mu_{g}=0.8$ & {$[0.32,0.80]$} & {$[0.80,0.89]$} & {$[-0.49,0.55]$} & {$[0.34,0.87]$} & {$[0.88,0.93]$} & {$[-0.55,0.61]$} \\
\hline & & 0.45 & 0.21 & 0.00 & 0.28 & 0.00 & 0.00 \\
\hline & & {$[-0.34,0.46]$} & {$[-0.27,0.14]$} & {$[0.19,0.47]$} & {$[-0.49,0.35]$} & {$[-0.33,0.18]$} & {$[0.15,0.45]$} \\
\hline & & 1.00 & 1.00 & 0.25 & 0.98 & 1.00 & 0.59 \\
\hline & $\mu_{g}=1.0$ & {$[0.02,0.78]$} & {$[0.70,0.83]$} & {$[-0.50,0.60]$} & {$[0.12,0.81]$} & {$[0.80,0.90]$} & {$[-0.50,0.64]$} \\
\hline & & 0.78 & 0.48 & 0.00 & 0.37 & 0.00 & 0.00 \\
\hline & & {$[-0.43,0.44]$} & {$[-0.45,-0.00]$} & {$[-0.43,-0.18]$} & {$[-0.65,0.29]$} & {$[-0.57,-0.14]$} & {$[-0.28,0.03]$} \\
\hline & & 1.00 & 1.00 & 1.00 & 1.00 & 1.00 & 0.98 \\
\hline \multicolumn{8}{|c|}{ Asymmetric Exogenous Forces } \\
\hline Technology & & $\overline{[0.96,0.98]}$ & {$[0.99,0.99]$} & {$[0.98,0.99]$} & 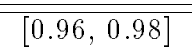 & {$[0.99,0.99]$} & {$[0.99,0.99]$} \\
\hline Shocks & & 0.00 & 0.00 & 0.00 & 0.00 & 0.00 & 0.00 \\
\hline & & {$[-0.13,0.35]$} & {$[-0.20,0.27]$} & {$[0.08,0.35]$} & {$[-0.93,0.47]$} & {$[-0.25,0.25]$} & {$[0.45,0.67]$} \\
\hline & & 1.00 & 1.00 & 1.00 & 1.00 & 1.00 & 0.37 \\
\hline Government and & $\mu_{g}=0.0$ & {$[0.97,0.98]$} & {$[0.99,0.99]$} & {$[-0.28,0.65]$} & {$[0.96,0.98]$} & {$[0.99,0.99]$} & {$[0.75,0.95]$} \\
\hline Technology & & 0.00 & 0.00 & 0.00 & 0.00 & 0.00 & 0.00 \\
\hline \multirow[t]{18}{*}{ Shocks } & & {$[-0.15,0.48]$} & {$[0.08,0.46]$} & {$[0.41,0.64]$} & {$[-0.91,-0.36]$} & {$[-0.20,0.30]$} & {$[0.50,0.69]$} \\
\hline & & 1.00 & 1.00 & 0.63 & 1.00 & 1.00 & 0.33 \\
\hline & $\mu_{g}=0.2$ & {$[0.95,0.98]$} & {$[0.99,0.99]$} & {$[-0.29,0.64]$} & {$[0.96,0.98]$} & {$[0.99,0.99]$} & {$[0.75,0.94]$} \\
\hline & & 0.00 & 0.00 & 0.00 & 0.00 & 0.00 & 0.00 \\
\hline & & {$[-0.16,0.38]$} & {$[-0.15,0.33]$} & {$[0.19,0.48]$} & {$[-0.93,-0.55]$} & {$[-0.34,-0.14]$} & {$[0.35,0.59]$} \\
\hline & & 1.00 & 1.00 & 1.00 & 1.00 & 1.00 & 0.80 \\
\hline & $\mu_{g}=0.5$ & {$[0.85,0.97]$} & {$[0.98,0.99]$} & {$[-0.26,0.69]$} & {$[0.95,0.99]$} & {$[0.99,0.99]$} & {$[0.78,0.95]$} \\
\hline & & 0.00 & 0.00 & 0.00 & 0.00 & 0.00 & 0.00 \\
\hline & & {$[-0.18,0.43]$} & {$[-0.24,0.25]$} & {$[-0.07,0.26]$} & {$[-0.94,-0.61]$} & {$[-0.00,-0.47]$} & {$[0.18,0.45]$} \\
\hline & & 1.00 & 1.00 & 1.00 & 1.00 & 1.00 & 1.00 \\
\hline & $\mu_{g}=0.8$ & {$[0.82,0.96]$} & {$[0.98,0.98]$} & {$[0.39,0.84]$} & {$[0.93,0.99]$} & {$[0.99,0.99]$} & {$[0.75,0.94]$} \\
\hline & & 0.00 & 0.00 & 0.00 & 0.00 & 0.00 & 0.00 \\
\hline & & {$[-0.84,0.21]$} & {$[-0.84,-0.54]$} & {$[-0.69,-0.17]$} & {$[-0.88,-0.25]$} & {$[-0.85,-0.67]$} & {$[-0.55,-0.21]$} \\
\hline & & 1.00 & 1.00 & 1.00 & 1.00 & 1.00 & 1.00 \\
\hline & $\mu_{g}=1.0$ & {$[0.60,0.92]$} & {$[0.94,0.97]$} & {$[-0.16,0.70]$} & {$[0.93,0.98]$} & {$[0.99,0.99]$} & {$[0.78,0.96]$} \\
\hline & & 0.05 & 0.00 & 0.00 & 0.00 & 0.00 & 0.00 \\
\hline & & {$[-0.20,0.40]$} & {$\left[\begin{array}{ll}-0.399 & 0.03\end{array}\right]$} & {$[-0.55,-0.31]$} & {$[-0.97,-0.75]$} & {$[-0.72,-0.43]$} & {$[-0.25,0.03]$} \\
\hline & & 1.00 & 1.00 & 1.00 & 1.00 & 1.00 & 1.00 \\
\hline
\end{tabular}

Notes: The first (third) row of each simulation reports the $90 \%$ range of the simulated cross country consumption (output) distribution, the second (fourth) the probability that the model generates the value we observe in the actual data. 